\title{
Using theory of change to design and evaluate public health interventions: a systematic review
}

\author{
Erica Breuer $^{1 *}$, Lucy Lee ${ }^{2}$, Mary De Silva² and Crick Lund ${ }^{1}$
}

\begin{abstract}
Background: Despite the increasing popularity of the theory of change (ToC) approach, little is known about the extent to which ToC has been used in the design and evaluation of public health interventions. This review aims to determine how ToCs have been developed and used in the development and evaluation of public health interventions globally.

Methods: We searched for papers reporting the use of "theory of change" in the development or evaluation of public health interventions in databases of peer-reviewed journal articles such as Scopus, Pubmed, Psychlnfo, grey literature databases, Google and websites of development funders. We included papers of any date, language or study design. Both abstracts and full text papers were double screened. Data were extracted and narratively and quantitatively summarised.

Results: A total of 62 papers were included in the review. Forty-nine (79 \%) described the development of ToC, 18 (29\%) described the use of ToC in the development of the intervention and 49 (79\%) described the use of ToC in the evaluation of the intervention. Although a large number of papers were included in the review, their descriptions of the ToC development and use in intervention design and evaluation lacked detail.

Conclusions: The use of the ToC approach is widespread in the public health literature. Clear reporting of the ToC process and outputs is important to strengthen the body of literature on practical application of ToC in order to develop our understanding of the benefits and advantages of using ToC. We also propose a checklist for reporting on the use of ToC to ensure transparent reporting and recommend that our checklist is used and refined by authors reporting the ToC approach.
\end{abstract}

Keywords: Theory of change, Intervention development, Evaluation, Programme theory, Public health, Systematic review

\section{Background}

Most public health interventions are inherently complex, with multiple interacting components, delivered at multiple levels. This complexity makes them difficult to evaluate using traditional experimental designs. Public health interventions often rely on ongoing quality improvement based on the implementation experience. Therefore, they may not reach the level of stability required to conduct evaluations such as randomised

\footnotetext{
* Correspondence: erica.breuer@uct.ac.za

${ }^{1}$ Alan J. Flisher Centre for Public Mental Health, Department of Psychiatry and Mental Health, University of Cape Town, 46 Sawkins Road, Rondebosch, 7700 Cape Town, South Africa

Full list of author information is available at the end of the article
}

controlled trials (RCTs) [1]. Some researchers propose that understanding the public health intervention's underlying theory of change (ToC) and its related uncertainties may improve the evaluation of complex health interventions [1-3].

Theory-driven evaluation is a collection of evaluation methods which emphasise the importance of understanding how and why a programme works in order to evaluate it $[4,5]$. By programme, we mean a set of organised activities or interventions supported by resources designed to achieve a specific result [6]. The theories are first made explicit and then used to see how the programme theory results in the intended outcomes [4]. 
There are several overlapping types of theory-driven evaluation approaches including logic models, logical frameworks, outcomes hierarchies, realist evaluation, and $\mathrm{ToC}[4,5]$.

ToC was developed by Weiss and others [7] within the tradition of theory-driven evaluation. Although definitions of ToC vary, we define it as an approach which describes how a programme brings about specific long-term outcomes through a logical sequence of intermediate outcomes [8]. The ToC is often developed using a backward mapping approach which starts with the long-term outcome and then maps the required process of change and the short- and medium-term outcomes required to achieve this [9]. During this process, the assumptions about what needs to be in place for the ToC to occur are made explicit as well as the contextual factors which influence the ToC. Additional elements of a ToC can include beneficiaries, research evidence supporting the ToC, actors in the context, sphere of influence, strategic choices and interventions, timelines and indicators [8]. These elements are usually presented in a diagram and/or narrative summary [8].

The ToC is usually developed in consultation with stakeholders through workshops or interviews although the participation of stakeholders can vary substantially in practice [10]. For example, some ToCs are developed through a series of workshops and meetings with a wide range of stakeholders including service users [11, 12] whereas others are developed by evaluators and funders using programme documentation [13, 14]. The resulting ToCs can be used as a framework for programme development and evaluation [8]. The ToC approach is method neutral and as such does not prescribe specific types of evaluation methods such as qualitative interviews or RCTs [15].

ToC is distinct from sociological or psychological theories which describe why change occurs although these may be used to inform the ToC [3]. For example, Bauer used an ecological model of community organising to inform a ToC for a capacity and advocacy initiative for residents to impact on public health policy and training of public health professionals [16].

ToC differs from other theory-driven approaches to evaluation despite similar origins. For example, although logic models outline the inputs, processes, outputs and outcomes of a programme in a similar manner to $\mathrm{ToC}$, they can be rigid and do not make explicit the causal pathways through which change happens in the way that $\mathrm{ToC}$ does [3]. Similarly, although logframes were initially developed to summarise discussions with stakeholders, funder-driven formats have largely reduced logframes to a results-based management tool [17]. Realist evaluation, on the other hand, comes from a perspective of scientific realism and focuses predominantly on the interaction between the context, mechanisms and outcomes of the programme. Usually used post hoc, evaluators seek to uncover the underlying programme theories. These theories are often more abstract than the theories developed through ToC or logic models [18]. The development of $\mathrm{ToC}$ has been influenced by Freirean thinking on how to create social change by empowering individuals [19]. Despite some fundamental differences in their theoretical underpinnings, many of these approaches are used interchangeably or together $[18,20]$.

$\mathrm{ToC}$ has been used widely in the development sector for programme development and evaluation by funders such as the UK's Department for International Development, Comic Relief, Grand Challenges Canada and the Gates Foundation [3, 19]. However, there has been no global systematic review to our knowledge on the use of ToC for the design and evaluation of public health interventions. Coryn et al. [4] conducted a review of theory-driven evaluation more broadly. They found 45 examples of theory-driven evaluation in the peer-reviewed literature between 1990 and 2009. These evaluations included education, crime and safety and transportation interventions. Roughly half $(21 / 45)$ were evaluations of health interventions [4]. A rapid analysis of the included papers in preparation for this review indicated that only three of these used ToC.

The lack of a systematic review means that there is no clear idea of how the ToC has been used and reported in the peer-reviewed and grey literature in relation to public health interventions. Given the increasing popularity of the ToC approach, understanding how it is has been used and described previously allows future users of the approach to learn from the work of others and build upon it. It also helps to move towards a more consistent way of using the ToC approach.

In this review, we sought to review both peer-reviewed and grey literature to determine how ToCs have been developed and used in the development and evaluation of public health interventions globally. Specifically, we sought to answer the following questions:

(1) How are ToCs for public health interventions developed and refined?

(2) How is the ToC approach used in the

(a) development of an intervention;

(b) implementation of the intervention;

(c) development of indicators for measurement;

(d) evaluation of the intervention, including statistical approaches; and

(e) conceptualisation/evaluation of the influence of context. 


\section{Methods}

The authors developed a protocol for this review which was agreed prior to the commencement of the study. This is available in Web Additional file 1.

\section{Inclusion and exclusion criteria}

The inclusion and exclusion criteria are listed in Table 1. In summary, we included studies of public health interventions which were defined as interventions which are intended to protect health or prevent or treat ill health in communities or populations [21]. We included papers describing interventions addressing any health issue in all populations which (a) described how a ToC approach was used to design, implement or evaluate a public health intervention or (b) described the development of a ToC for a public health intervention. Evaluation study designs included longitudinal studies, quantitative surveys, case study research [22] and qualitative studies.

We required papers to specifically mention that they used "theory of change" and excluded those who did not for the following reasons. Firstly, as described above, there are a range of overlapping definitions for ToC and other programme evaluation methods. Given the often minimal amount of detail provided about the programme theory in papers, and especially in abstracts, it would be difficult to enforce a standard criteria for ToC against which papers could be evaluated for inclusion. Secondly, piloting the initial broad search strategy (including all synonyms for $\mathrm{ToC}$ and programme logic) returned more than 20,000 hits in only three databases. By refining the criteria to specify $\mathrm{ToC}$ by name, we were able to thoroughly explore literature which explicitly selfidentified using ToC.

\section{Table 1 Inclusion and exclusion criteria}

Inclusion criteria:

- Describes or evaluates a public health intervention defined as any intervention which is intended to protect health or prevent or treat ill health in communities or populations [1]

- Self-identifies as using a ToC approach and specifically mentions "theory of change"

- Describes how a ToC was developed or how ToC was used in the design, evaluation and/or implementation of a public health intervention

- Any evaluation design

- Any date

- Any language

- Any country

Exclusion criteria:

- Conceptual/methodological or advocacy papers unless they include an example of how a ToC was developed or how ToC was used in the design, evaluation and/or implementation of a public health intervention

- Review articles

- Specific psychological, sociological or organisational theory (unless used to inform the ToC)

- ToC in which the outcome is a change within an individual rather than change at population level.
As the focus of this review was on public health interventions, we excluded papers in which the long-term outcome of the ToC was a change within an individual rather than change in the population. For example, a ToC describing how cognitive behavioural therapy may impact on an individual's cognitive processes and behaviour would be a change within the individual. However, if the focus of the ToC was on how a cognitive behavioural therapy intervention impacted the prevalence of depression would be change in the population. We excluded reviews and methodological or advocacy papers unless they included an example of how a ToC was developed or how ToC was used in the design, evaluation and/or implementation of a public health intervention. We did not limit the inclusion by date, language, study design or type of publication.

\section{Search strategy}

The database searches were conducted between the 16th November and the 4th December 2013 by EB. The main search term used was "theory of change". Where the database allowed, we limited this to health or healthcare and to humans. We searched databases of peer-reviewed journal articles (Scopus, PubMed, PsychInfo, Science Citation Index, Social Science Citation Index, Academic Search Premier, Africa-Wide Information, CINAHL and BIOSIS). An example of a search string used for PyschInfo was "theory of change" AND ("health" OR "healthcare" OR "health services" OR "medicine"). We also searched grey literature databases (The Directory of Published Proceedings OpenGrey, Disability Archive UK, Eldis, Popline, DFID Research for Development, SciDevNet and World Bank Documents and Reports) and the first 50 pages of a Google search. The websites of Comic Relief, DFID, Grand Challenges Canada, The Bill and Melinda Gates Foundation, HIVOS, World Vision, the Robert Wood Johnson foundation, Actknowledge and the Theory of Change Community were also searched. In addition, we contacted experts in the field and sent requests for papers to two existing global mailing lists for evaluators: MandENEWS and Pelican.

\section{Screening and eligibility}

Following the search of databases of peer-reviewed journal articles, the titles and abstracts of the search results from peer-reviewed papers were exported into Endnote [23] where duplicates and irrelevant titles were removed. The peer-reviewed journal articles found through contact with experts were added to this. The titles and abstracts were double screened by EB and LL against the inclusion and exclusion criteria. Once the abstracts were screened, the full papers or reports of the included abstracts were obtained and assessed for eligibility by both reviewers. 
Following the grey literature search as described above, all potentially relevant results were saved into Evernote [24]. These were double screened by both reviewers against the inclusion and exclusion criteria.

Any differences between authors' opinions were resolved via discussion throughout the review process.

\section{Data extraction and analysis}

The data from the papers were extracted by the first author (EB) onto a data extraction form. This included information on authors, publication dates, the type of interventions and outcomes, the development of $\mathrm{ToC}$, the use of $\mathrm{ToC}$ in the design, implementation and evaluation of the intervention and the influence of context. The data collection form also included key principles of theory-driven evaluation proposed by Coryn et al. [4]. These included how the programme theory was (a) formulated, (b) used to formulate and prioritise evaluation questions, (c) plan and conduct evaluations, (d) inform the measurement of constructs in the programme theory and (e) provide a causal explanation. Where a paper described or showed a ToC, we assessed what elements of $\mathrm{ToC}$ they presented. The list of $\mathrm{ToC}$ elements was adapted from Vogel and included context, long-term change, process/sequence of change and assumptions [8]. However, as there is no agreed upon assessment of quality for papers reporting $\mathrm{ToC}$, we did not asses the quality of the included papers. We did not contact authors for additional information.

Descriptive statistics were calculated using STATA 13 [25]. The papers were compared, evaluated and summarised narratively in relation to review questions. Due to the heterogeneity of the study designs, interventions and outcomes included in this review, a meta-analysis was not conducted.

\section{Results \\ Search results}

In total, 566 abstracts were screened, resulting in 200 full text peer-reviewed articles which were assessed for eligibility. An additional 65 records were identified from the grey literature search and screened for eligibility. A total of 62 papers were included [1, 12-14, 16, 26-82]. Figure 1 is adapted from the PRISMA guidelines [83] and summarises the search process and results.

\section{Included studies}

The publication dates of the papers range between 1999 and 2013, with a steady increase in papers over time (Fig. 2). The majority were published in English in peerreviewed journals, but we also included $\mathrm{PhD}$ theses, presentations and NGO reports from the grey literature. Most of the research was conducted in the USA or the UK. More details are provided in Table 2. Four pairs of papers are reported on the same public health interventions $[1,13,42,43,54,60,81,82]$. However, as the primary interest of this paper is how the use of $\mathrm{ToC}$ is described in reports and peer-reviewed journal articles, we have included them as separate papers.

A variety of types of public health interventions reported using ToC in the design, development and evaluation of public health interventions (Table 3). These included systems of care for adolescents with behavioural and emotional difficulties $[12,26,50,53,54,56$, $61,65,80-82]$, substance use interventions [27, 49], domestic violence interventions [29], comprehensive community initiatives $[13,16,35,62,81]$, medication supply among community health workers [40] and integrated district level mental healthcare plans in low- and middle-income countries [55].

\section{Development of ToCs}

Forty-nine papers (79\%) included some information on the ToC development process. Forty-three percent $(n=27)$ of the papers developed their ToCs prospectively and 19.4\% $(n=12)$ retrospectively. The remainder either developed their ToC during project replanning $(n=3.5 \%)$ or did not specify when they developed their ToC $(n=20,32 \%)$.

The ToCs were developed using workshops $[28,34$, $47,48,55,63,64,72,76]$ and working groups [12, 53, $54,61,68,69,82]$, document reviews $[16,35,44,56,67$, $71]$, interviews and discussions $[16,27,29,35,40,44,47$, $56,57,62,65,66,73,80]$, surveys [31, 67], programme observation [16, 44, 45, 56, 67], literature reviews [33, $40,68,69,80]$ and existing conceptual frameworks or theory [33, 40, 42-44, 51, 64, 68, 69]. The ToC development included consultations or interviews with the following stakeholders: programme staff $[27,38,40,44,45$, $52,54,57,63,65-67,72,73,82]$, management $[12,57$, $61,66,70,77,82]$, families [12, 26, 54, 65, 77, 82], service users $[39,47,50,61,65]$, experts $[40,64]$ and evaluators $[13,14,38,44,52,58,61,70,75,77,81]$. Many used multiple methods, for example, Mookheriji and Lafond used immunisation programme theory and discussion with programme stakeholders, including immunisation experts, to develop a ToC of routine immunisation performance [64]. They used a case study approach to evaluate immunisation performance and then refined the ToC based on the results of this evaluation and a stakeholder workshop.

The resultant ToCs were described using narrative summaries $(n=15,34.1 \%)$, diagrams $(n=22,50 \%)$ or both $(n=6,13.6 \%)$. In one case, a table was used. Table 4 outlines the components of the ToCs that were described. Almost all of the ToCs outlined the long-term outcome required, and the majority described the process or sequence of change. However, assumptions and indicators were displayed or described infrequently. 


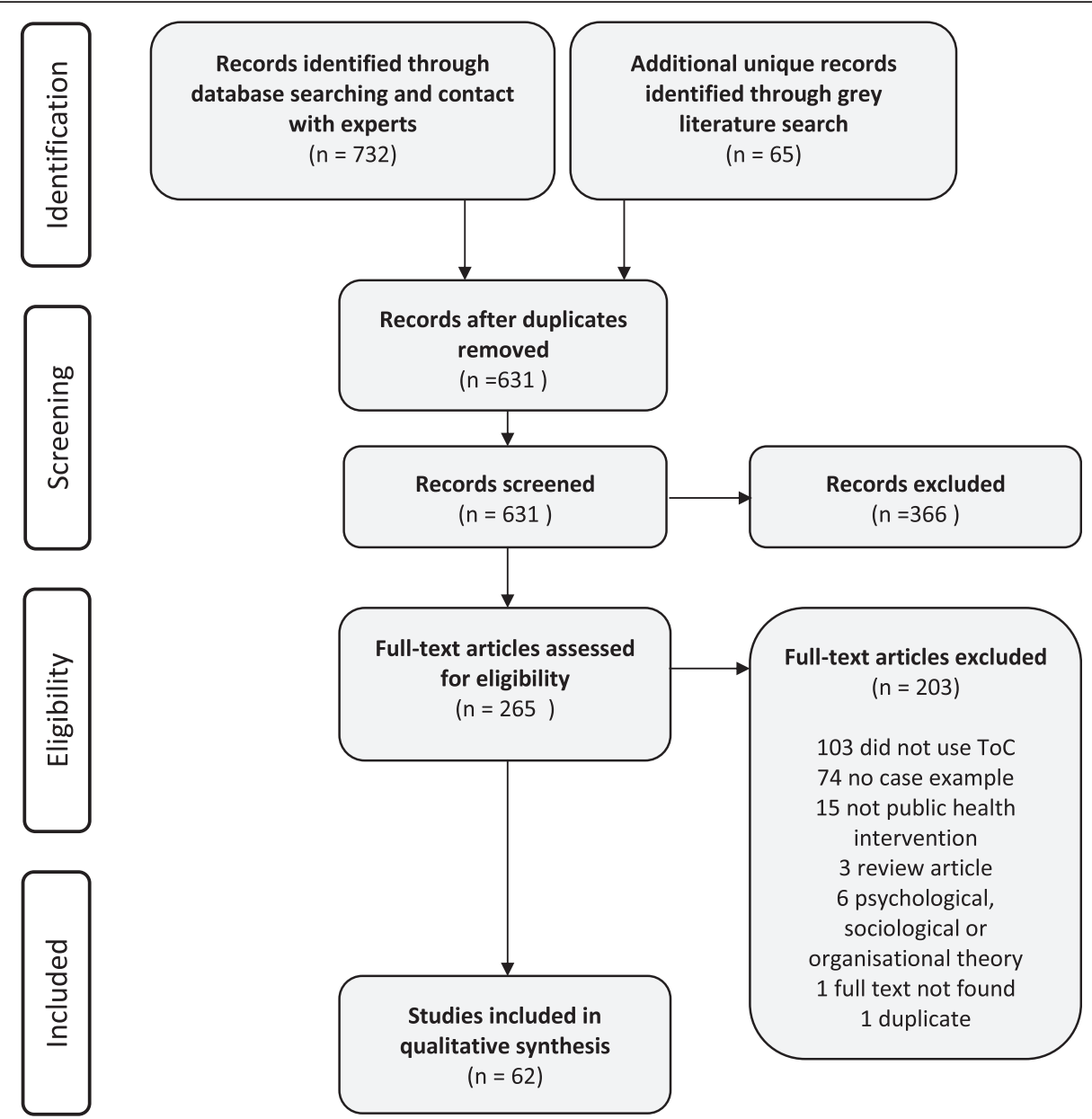

Fig. 1 Results of database, abstract and full text screening

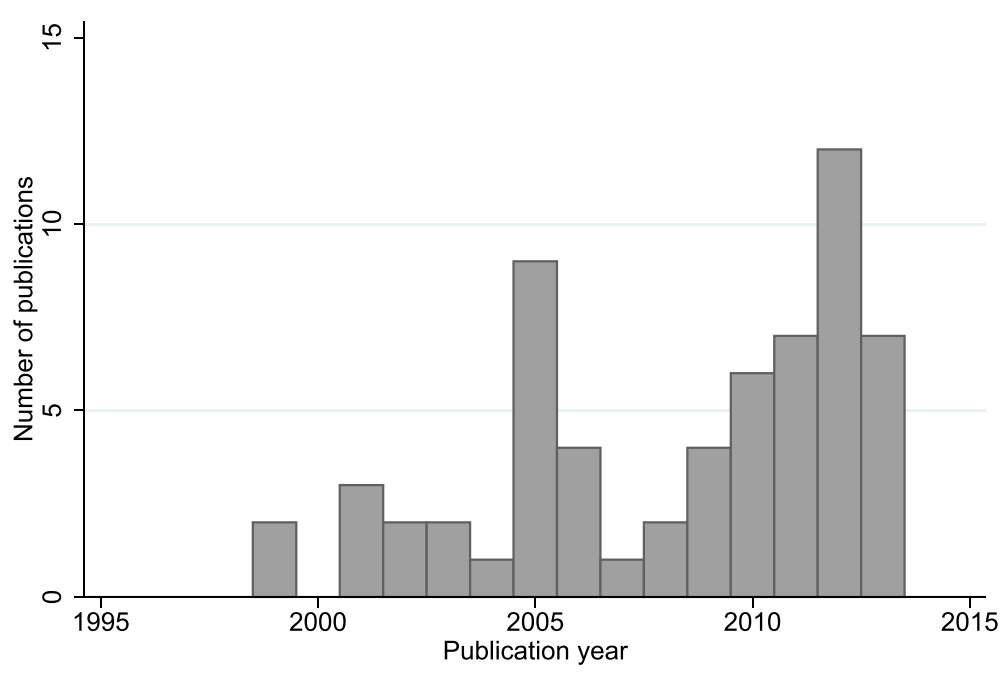

Fig. 2 Histogram of number of publications per year 
Table 2 Basic descriptive statistics of included papers

\begin{tabular}{ll}
\hline Variable & $n=62$ \\
& $n(\%)$ \\
\hline Language & $60(96.7 \%)$ \\
English & $2(3.2 \%)$ \\
Spanish & \\
Country & $28(45.2 \%)$ \\
USA & $20(32.3 \%)$ \\
UK & $5(8.1 \%)$ \\
Other high-income country & $9(14.5 \%)$ \\
Low- and middle-income country & \\
Type of publication & $15(24.2 \%)$ \\
Grey literature & $47(75.8 \%)$ \\
Peer-reviewed journal article & $31(50.0 \%)$ \\
$\quad$ Public health, medicine and nursing & $3(4.8 \%)$ \\
$\quad$ Psychology & $6(9.7 \%)$ \\
$\quad$ Social policy and social work & $5(8.1 \%)$ \\
Evaluation methods & $2(3.2 \%)$ \\
$\quad$ Other & \\
Use of TOC & $49(79.0 \%)$ \\
Describes development of ToC & $18(29.0 \%)$ \\
Describes the use of ToC in the development & \\
Describes the use of ToC in the evaluation of & $49(79.0 \%)$ \\
\hline
\end{tabular}

\section{Using ToCs to design public health interventions}

Eighteen papers $(29 \%)$ described the use of $\mathrm{ToC}$ in the development of a public health intervention. The majority of these reported that they used the $\mathrm{ToC}$ as a framework for the intervention $[12,31,42,43,70]$ or as a basis for a strategic plan $[61,68,69,76,82]$. Some examples of how ToCs were used to design public health interventions follow. Basson et al. used formative research to develop a $\mathrm{ToC}$ for a workplace wellness intervention for HIV-affected nurses and presented this programme theory as a framework for future research. Lund et al. used stakeholder workshops to develop their ToC and then used this to refine the substance and delivery of integrated district mental healthcare plans in five low- and middle-income countries [55]. A few presentations and papers reporting the development of systems of care for children with behavioural difficulties used the $\mathrm{ToC}$ as an outline of their public health intervention and as a basis for their strategic plan [12, 61, 65]. Chandani et al. [40] used the $\mathrm{ToC}$ to frame the results of their formative work and used the ToC to identify interventions to address the bottlenecks to the availability of essential medicines among community health workers in Ethiopia, Malawi and Rwanda.
Using ToCs to evaluate public health interventions

Forty-nine papers $(79 \%)$ describe the use of $\mathrm{ToC}$ in the evaluation of the intervention. This includes the development of indicators, the overall evaluation design and data analysis.

The development of indicators used in the ToC was described in 28 papers. The indicators were often developed from the short-, medium- or long-term outcomes described in the ToC $[27,35,38,58,65,74,81,84]$. Thirty-two (51.6 \%) measured process constructs, 28 $(45.2 \%)$ measured outcome constructs and 9 (14.5\%) measured contextual constructs described in the ToC. Only two papers $[12,82]$ explicitly described the use of ToC to identify indicators for ongoing monitoring of the implementation of the intervention.

The majority of papers $(62.9 \%)$ reported formulating their evaluation questions around the ToC. However, the papers varied in the amount of detail they provided on this process. A common description was that the ToC was used to provide a framework for the evaluation $[27,32,33,48,64,72,74,78,79,81,82]$. Others reported that they used the evaluation to develop [39], refine [40] or validate the $\mathrm{ToC}$ [64]. Two papers reported that their evaluation was guided by testing the assumptions in the ToC [29,34].

The data collection and analysis methods used varied greatly across papers. Data collected for the evaluation included routinely collected data [33, 44], customdesigned surveys [13, 16, 32, 72, 76, 79] and qualitative data. Qualitative data collection methods included interviews [13, 27, 35, 47, 71, 73, 75, 79], programme observation [13, 27, 35], programme documentation $[13,35,71,75,79]$ and visual evidence [32]. The quantitative data analysis methods were strongly linked to the types of data collected and included descriptive statistics [33], inferential statistics [27, 40, 42, 43, 74, 78], multilevel modelling [16] and path analysis [41]. Other methods included case study approaches [16, 33, 36, 64] and iterative thematic analysis [71] whereas others did not explicitly state their specific data analysis approach [14, 77].

Few papers explicitly explored the influence of context of the intervention in relation to ToC. Although some ToCs mentioned context, particularly those with a realist evaluation focus, there was little description of how context affected the interpretation of the evaluation. There were some exceptions [40, 56, 64, 72]. Mookherji and LaFond used a case study approach to explore what worked within and between immunisation programme contexts to identify common factors influencing immunisation performance in Ghana, Ethiopia and Cameroon [64]. For example, political and social commitment to routine immunisation was seen as a key factor in influencing immunisation performance although it was 
Table 3 Characteristics of studies included in the review and reported aspects of the ToC process

\begin{tabular}{|c|c|c|c|c|c|c|}
\hline Reference & Location(s) & Brief description of program & Health outcome & $\begin{array}{l}\text { Development } \\
\text { of TOC }\end{array}$ & $\begin{array}{l}\text { TOC in intervention } \\
\text { development }\end{array}$ & $\begin{array}{l}\text { ToC in } \\
\text { evaluation }\end{array}$ \\
\hline $\begin{array}{l}\text { Andersen, Nesman et al. } \\
\text { (2012) [26] }\end{array}$ & USA & $\begin{array}{l}\text { Tampa Hillsborough integrated network for kids: } \\
\text { respite care for families with seriously emotionally } \\
\text { disturbed children }\end{array}$ & Reduction in caregiver burden & $x$ & & \\
\hline $\begin{array}{l}\text { Andreas, Ja et al. } \\
\text { (2010) [27] }\end{array}$ & USA & $\begin{array}{l}\text { Peer community approach to prevent substance } \\
\text { use and recidivism in men and women in recovery } \\
\text { who have been incarcerated }\end{array}$ & Prevention of substance abuse relapse & $x$ & & $x$ \\
\hline AusAID (2010) [28] & Papua New Guinea & $\begin{array}{l}\text { Strengthen sector wide response to HIV in Papua } \\
\text { New Guinea }\end{array}$ & $\begin{array}{l}\text { Stable HIV incidence rate; improved care for } \\
\text { people living with HIV/AIDS }\end{array}$ & $x$ & & \\
\hline $\begin{array}{l}\text { Bacchus, Bewley et al. } \\
\text { (2010) [29] }\end{array}$ & UK & $\begin{array}{l}\text { Guidelines, staff training, inclusion of routine enquiry } \\
\text { for domestic violence with all patients, and referral } \\
\text { of women disclosing violence to an on-site advocacy } \\
\text { service. }\end{array}$ & $\begin{array}{l}\text { Reduction in severity and frequency of abuse. } \\
\text { Improved safety and access to resources }\end{array}$ & $x$ & & $x$ \\
\hline $\begin{array}{l}\text { Barton, Powers et al. } \\
\text { (2001) [30] }\end{array}$ & USA & $\begin{array}{l}\text { Promoting positive youth development for young } \\
\text { people }\end{array}$ & $\begin{array}{l}\text { Reduction in drug and alcohol use, increase } \\
\text { in immunisation rates }\end{array}$ & & & $x$ \\
\hline $\begin{array}{l}\text { Basson and Roets } \\
\text { (2013) [31] }\end{array}$ & South Africa & $\begin{array}{l}\text { A workplace wellness programme for HIV affected } \\
\text { nurses }\end{array}$ & Positive health and well-being of nurses & $x$ & $x$ & \\
\hline Bauer (1999) [16] & USA & $\begin{array}{l}\text { Oakland Community-Based Public Health Initiative: } \\
\text { a capacity and advocacy initiative for residents to } \\
\text { impact on public health policy and training of } \\
\text { public health professionals }\end{array}$ & Nil specific & $x$ & & $x$ \\
\hline $\begin{array}{l}\text { Bauld, Judge et al. } \\
\text { (2005) [32] }\end{array}$ & UK & $\begin{array}{l}\text { Health action zones: a multi-area study in } 26 \text { local } \\
\text { health areas aiming to identify and address the } \\
\text { public health needs of the local area, to increase } \\
\text { effectiveness and efficiency of services and develop } \\
\text { partnerships }\end{array}$ & Improved health and reduced inequality. & & & $x$ \\
\hline $\begin{array}{l}\text { Beeston, Robinson et al. } \\
\text { (2011) [33] }\end{array}$ & UK & A strategy for reducing alcohol related harm & Reduced alcohol related harms & $x$ & & $x$ \\
\hline Bhattacharjee (2013) [34] & India & $\begin{array}{l}\text { A multipronged programme targeting sex workers, } \\
\text { their partners and the community to increase } \\
\text { condom use and reduce violence towards sex } \\
\text { workers }\end{array}$ & $\begin{array}{l}\text { Increase in protected sex and decrease in } \\
\text { STI/HIV transmission among sex workers }\end{array}$ & $x$ & $x$ & $x$ \\
\hline Birkby (2001) [35] & USA & $\begin{array}{l}\text { Community partnerships for protecting children } \\
\text { initiative on child maltreatment consisting of } 5 \\
\text { strategic elements including casework training, } \\
\text { family decision-making, a hotline, community } \\
\text { resource teams and substance abuse prevention } \\
\text { and treatment }\end{array}$ & Reduction in serious injury & $x$ & & $x$ \\
\hline Bonner (2003) [36] & UK & $\begin{array}{l}\text { Programme aimed at reducing drug taking and } \\
\text { drug related harm }\end{array}$ & $\begin{array}{l}\text { Reduction in drug taking and drug-related } \\
\text { harm among urban young people }\end{array}$ & & & $x$ \\
\hline $\begin{array}{l}\text { Brown, Hawkins et al. } \\
\text { (2013) [37] }\end{array}$ & USA & $\begin{array}{l}\text { Communities that care: a manualised system for } \\
\text { community coalitions to influence human and } \\
\text { financial resources to address adolescent health } \\
\text { and behaviour problems }\end{array}$ & Reduction in adolescent behaviour problems. & & & $x$ \\
\hline
\end{tabular}

Basson and Roets

(2013) [31]

Bauer (1999) [16]

Bauld, Judge et al

(2005) [32]

Beeston, Robinson et al.

(2011) [33]

Bhattacharjee (2013) [34] India

and behaviour problems 
Table 3 Characteristics of studies included in the review and reported aspects of the ToC process (Continued)

\begin{tabular}{|c|c|c|}
\hline $\begin{array}{l}\text { Carr, Lhussier et al. } \\
\text { (2008) [38] }\end{array}$ & UK & $\begin{array}{l}\text { A walking group as part of the Positive Health } \\
\text { Programme funded by the Neighbourhood } \\
\text { Renewal Fund }\end{array}$ \\
\hline $\begin{array}{l}\text { Carroll, David et al. } \\
\text { (2005) [39] }\end{array}$ & UK & Workplace wellness program \\
\hline $\begin{array}{l}\text { Chandani, Noel et al. } \\
\text { (2012) [40] }\end{array}$ & $\begin{array}{l}\text { International multi- } \\
\text { country }\end{array}$ & $\begin{array}{l}\text { Medication supply chains for community health } \\
\text { workers in Rwanda, Ethiopia and Malawi }\end{array}$ \\
\hline $\begin{array}{l}\text { Cole, Hogg-Johnson } \\
\text { et al. (2006) [41] }\end{array}$ & Canada & Workplace economic program \\
\hline $\begin{array}{l}\text { De La Rosa, Perry et al. } \\
\text { (2005) [42] }\end{array}$ & USA & $\begin{array}{l}\text { A family based home visit intervention during } \\
\text { pregnancy and after the birth of the first child }\end{array}$ \\
\hline $\begin{array}{l}\text { De La Rosa, Perry et al. } \\
\text { (2009) [43] }\end{array}$ & USA & $\begin{array}{l}\text { A family based home visit intervention during } \\
\text { pregnancy and after the birth of the first child }\end{array}$ \\
\hline $\begin{array}{l}\text { Dixon-Woods, Bosk } \\
\text { et al. (2011) [44] }\end{array}$ & USA & $\begin{array}{l}\text { An intervention in intensive care units to reduce } \\
\text { central venous catheter bloodstream infections }\end{array}$ \\
\hline $\begin{array}{l}\text { Dixon-Woods, Tarrant } \\
\text { et al. (2010) [45] }\end{array}$ & UK & $\begin{array}{l}\text { Safer Patient Initiative: introduction of patient } \\
\text { safety into hospital management, culture and } \\
\text { practice. }\end{array}$ \\
\hline Goss-Power (2005) [46] & USA & $\begin{array}{l}\text { VASE: a school for adolescents with emotional } \\
\text { and behavioural disturbances }\end{array}$ \\
\hline $\begin{array}{l}\text { Gray and Seddon } \\
\text { (2005) [47] }\end{array}$ & UK & $\begin{array}{l}\text { Two programmes aimed at children in "trouble" } \\
\text { at school, truancy and risk of social exclusion. } 1 . \\
\text { "Kick it" Football Project which included mentoring } \\
\text { and drug education, 2. The Salford Anti-Rust } \\
\text { gardening project using mentoring using } \\
\text { horticulture }\end{array}$ \\
\hline Gregor (2009) [48] & UK & $\begin{array}{l}\text { Programme which enables partnership between } \\
\text { public and third sector organisations to deliver } \\
\text { awareness-raising programs }\end{array}$ \\
\hline Henderson (2004) [49] & USA & $\begin{array}{l}\text { A substance abuse treatment programme for } \\
\text { homeless people }\end{array}$ \\
\hline $\begin{array}{l}\text { Hernandez and Hodges } \\
\text { (2006) [12] }\end{array}$ & USA & $\begin{array}{l}\text { Interagency service planning for youth who had } \\
\text { been arrested and involved in juvenile probation }\end{array}$ \\
\hline $\begin{array}{l}\text { Illinois Caucus for } \\
\text { Adolescent Health } \\
\text { (2013) [50] }\end{array}$ & USA & $\begin{array}{l}\text { A network of youth and adults who advocate within } \\
\text { school, family and healthcare systems to support } \\
\text { sexual health, rights and identities of youth }\end{array}$ \\
\hline $\begin{array}{l}\text { Kemp, Harris et al. } \\
\text { (2013) [51] }\end{array}$ & Australia & An ante- and post-natal home visiting program \\
\hline
\end{tabular}

factory workers

Appropriate receipt of treatment for common $x$

childhood illness; Availability of usable and

quality medicines for appropriate treatment

of childhood illnesses

Reduction in pain intensity and disability

Improved social support, caregiver behaviours, $x$ family interactions and decreased personal

problems affecting parenting.

Multiple including improved immunisation $x$ rates, connection with a medical home and

maternal achievement of economic

self-sufficiency.

Decrease in intensive care unit mortality,

hospital mortality, catheter related infections,

ventilator associated pneumonia

Increased patient safety in hospitals

Nil specific

No specific health outcomes mentioned $\quad X$ (mechanisms for change only)

barriers to access

Sobriety, improved medical health

Impacts school, family and healthcare systems $X$ in priority areas 
Table 3 Characteristics of studies included in the review and reported aspects of the ToC process (Continued)

\begin{tabular}{|c|c|c|c|c|c|c|}
\hline & & & $\begin{array}{l}\text { Multiple including improved pre and postnatal } \\
\text { maternal health and increased engagement } \\
\text { with services }\end{array}$ & & & \\
\hline $\begin{array}{l}\text { Knowlton and Phillips } \\
\text { (2012) [14] }\end{array}$ & USA & $\begin{array}{l}\text { A five-arm strategic funding model to improve food } \\
\text { security for children in the USA }\end{array}$ & Improved US food security & $x$ & & $x$ \\
\hline $\begin{array}{l}\text { Kreger, Sargent et al. } \\
\text { (2011) [52] }\end{array}$ & USA & $\begin{array}{l}\text { A network of coalitions and technical assistance } \\
\text { programmes who use an environmental justice } \\
\text { approach to reduce risk factors for smoking }\end{array}$ & Healthier children and environments & $x$ & $x$ & $x$ \\
\hline $\begin{array}{l}\text { Levinson-Johnson } \\
\text { (2012) [53] }\end{array}$ & USA & $\begin{array}{l}\text { A system of care for youth with behavioural and } \\
\text { emotional problems and their families }\end{array}$ & Various health systems level changes & $x$ & $x$ & $x$ \\
\hline $\begin{array}{l}\text { Levison-Johnson and } \\
\text { Wenz-Gross (2010) [54] }\end{array}$ & USA & $\begin{array}{l}\text { A system of care for youth with behavioural and } \\
\text { emotional problems and their families }\end{array}$ & Not described & $x$ & & \\
\hline $\begin{array}{l}\text { Lund, Tomlinson et al. } \\
\text { (2012) [55] }\end{array}$ & $\begin{array}{l}\text { International multi- } \\
\text { country }\end{array}$ & $\begin{array}{l}\text { Programme for improving mental healthcare (PRIME): } \\
\text { district specific mental health care plans which are } \\
\text { integrated into routine health services }\end{array}$ & Not described & $x$ & $x$ & $x$ \\
\hline $\begin{array}{l}\text { Macfarlane, Greenhalgh } \\
\text { et al. (2011) [56] }\end{array}$ & UK & $\begin{array}{l}\text { Whole-scale transformation of stroke, kidney and } \\
\text { sexual health services including human resource } \\
\text { management }\end{array}$ & $\begin{array}{l}\text { Various including culture of health service } \\
\text { and quality of care and service provision }\end{array}$ & $x$ & & $x$ \\
\hline Mackenzie (2006) [57] & UK & $\begin{array}{l}\text { Starting well: intensive home visiting services for } \\
\text { families of new babies in } 2 \text { areas in Scotland }\end{array}$ & Not described & $x$ & & $x$ \\
\hline $\begin{array}{l}\text { Mackenzie and Blamey } \\
\text { (2005) [58] }\end{array}$ & UK & A multipronged heart disease prevention program & Reduced coronary heart disease & $x$ & & $x$ \\
\hline $\begin{array}{l}\text { Mackenzie, Blamey et al. } \\
\text { (2007) [59] }\end{array}$ & UK & $\begin{array}{l}\text { Choose life: a national strategy to reduce suicide in } \\
\text { Scotland }\end{array}$ & $\begin{array}{l}20 \% \text { reduction in suicide rates over a 10-year } \\
\text { period }\end{array}$ & & & $x$ \\
\hline $\begin{array}{l}\text { Mackenzie, O'Donnell } \\
\text { et al. (2010) [1] }\end{array}$ & UK & $\begin{array}{l}\text { Keep Well: a programme to identify those at risk of } \\
\text { ill health and offered health checks and preventative } \\
\text { services within primary and secondary care }\end{array}$ & $\begin{array}{l}\text { Decreasing inequalities in cardiovascular } \\
\text { morbidity and mortality in Scotland }\end{array}$ & & & $x$ \\
\hline $\begin{array}{l}\text { Mackenzie, Reid et al. } \\
\text { (2012) [60] }\end{array}$ & UK & $\begin{array}{l}\text { Keep Well: the programme to identify those at risk } \\
\text { of ill health and offered health checks and } \\
\text { preventative services within primary and secondary } \\
\text { care }\end{array}$ & $\begin{array}{l}\text { Decreasing inequalities in cardiovascular } \\
\text { morbidity and mortality in Scotland }\end{array}$ & & & \\
\hline Maselli (2012) [61] & USA & $\begin{array}{l}\text { A comprehensive system of care which avoids } \\
\text { re-traumatising children and youth with severe } \\
\text { emotional challenges }\end{array}$ & Nil specific & $x$ & $x$ & $x$ \\
\hline Mason (2005) [62] & UK & $\begin{array}{l}\text { The Timely Tales: a community development and } \\
\text { community arts project (part of a larger Health } \\
\text { Action Zone Project) }\end{array}$ & None described & $x$ & & $x$ \\
\hline $\begin{array}{l}\text { McQuiston, Choi-Hevel } \\
\text { et al. (2001) [63] }\end{array}$ & USA & $\begin{array}{l}\text { A culture specific programme to empower lay } \\
\text { health advisers to promote sexual health and } \\
\text { reduce sexually transmitted diseases }\end{array}$ & $\begin{array}{l}\text { Promotion of sexual health and reduction of } \\
\text { sexually transmitted diseases including HIV }\end{array}$ & $x$ & $x$ & \\
\hline $\begin{array}{l}\text { Mookherji and LaFond } \\
\text { (2013) [64] }\end{array}$ & $\begin{array}{l}\text { International multi- } \\
\text { country }\end{array}$ & $\begin{array}{l}\text { Africa Routine Immunisation System Essentials } \\
\text { (ARISE): using lessons from existing immunisations }\end{array}$ & $\begin{array}{l}\text { Improved immunisation performance and } \\
\text { equity }\end{array}$ & $x$ & & $x$ \\
\hline
\end{tabular}


Table 3 Characteristics of studies included in the review and reported aspects of the ToC process (Continued)

Morilus-Black, McCarthy USA

et al. (2012) [65]

Reid and Botma (2012) South Africa

[66]

Riley, Byng et al. (2008)

[67]

Rivera, Martorell et al.

(2011) [68]

Rodriguez, Betanzos-Reyes International multiet al. (2011) [69] country

Scanlon, Beich et al. USA (2012) [70]

Schierhout, Hains et al. Australia (2013) [71]

Secker, Bowers et al. UK

(2005) [72]

Smith and Barnes

(2013) [73]

Suarez-Balcazar

(2005) [74]

Tran (2009) [75]

Tucker, Liao et al.

(2006) [76]

Vander Stoep, Williams

et al. (1999) [77]

Veerman, De Kemp et al. Netherlands (2003) [78]

von dem Knesebeck, Germany

Joksimovic et al.

(2002) [79]

Walker and Matarese

(2011) [80] programmes that have achieved solid advances in

immunisation

An integrated system of care for children and families Improved care and referrals

experiencing social and/or behavioural challenges

A programme which aims to expand public services Nil specific

to children with biomedical healthcare needs related

to HIV

The Lewisham Depression Programme: a multifaceted programme which included marketing of the program training and a depression recognition audit

A master plan for the improvement of nutrition in Mesoamerica

A multifaceted strategic plan to eliminate malaria transmission in Mesoamerica

Quality improvement alliance: to improve quality in the healthcare system

A continuous quality improvement programme in primary health care centres

Preretirement health advice and services for people aged 50-65 years

A whole systems approach to prevention of ill health

A community intervention to assist community members in accessing health resources through the project's home web page and the Internet.

Provision of mental health advocacy delivered by a Chinese advocate with Cantonese and Mandarin skills

Community strategies driven by 40 community coalitions to eliminate disparities in racial or ethnic groups for priority health areas

A family-centred system of care by community-based teams for youth with mental health needs

Families First: a home-based intervention for children with behaviour problems

Systems interventions to improve local coordination of health and social care

Not described

Multiple including decreased mortality and $\quad x$ increased maternal and child health

Eliminating local transmission of malaria in $x$ Mesoamerica

Improvement in key community and population health outcomes

Changes in delivery of guideline schedules services, focusing on diabetes and preventive care

Nil mentioned

mproved quality of life, reduced social exclusion $\quad x$ and reduced need for acute hospital care for

older people

Nil specific 
Table 3 Characteristics of studies included in the review and reported aspects of the ToC process (Continued)

\begin{tabular}{|c|c|c|c|c|c|c|}
\hline $\begin{array}{l}\text { Weitzman, Silver et al. } \\
\text { (2002) [13] }\end{array}$ & & $\begin{array}{l}\text { Urban Health Initiative: a citywide multi-sector } \\
\text { planning initiative }\end{array}$ & $\begin{array}{l}\text { Improved health and safety outcomes for } \\
\text { children and youth }\end{array}$ & & & \\
\hline $\begin{array}{l}\text { Weitzman, Mijanovich } \\
\text { et al. (2009) [81] }\end{array}$ & USA & $\begin{array}{l}\text { Urban Health Initiative: a citywide multi-sector } \\
\text { planning initiative }\end{array}$ & $\begin{array}{l}\text { Improved health and safety outcomes for } \\
\text { children and youth }\end{array}$ & $x$ & & $x$ \\
\hline $\begin{array}{l}\text { Wenz-Gross and } \\
\text { DuBrino (2012) [82] }\end{array}$ & USA & $\begin{array}{l}\text { A which programme aims to decrease and prevent } \\
\text { youths with serious emotional disturbance from } \\
\text { becoming involved in the courts }\end{array}$ & $\begin{array}{l}\text { Various including increased youth functioning } \\
\text { and behavioural adjustment }\end{array}$ & $x$ & $x$ & $x$ \\
\hline
\end{tabular}


Table 4 Components of ToC in the papers where a ToC was displayed or described. Essential and additional components adapted from Vogel [8]

\begin{tabular}{ll}
\hline ToC components & $n=44$ \\
& $n(\%)$ \\
\hline Essential & $40(90.9 \%)$ \\
Long-term change & $33(75 \%)$ \\
Process/sequence of change & $24(54.5 \%)$ \\
Context & $7(15.9 \%)$ \\
Assumptions & \\
Additional & $23(52.3 \%)$ \\
Strategic choices and intervention options & $20(45.5 \%)$ \\
Beneficiaries & $13(29.5 \%)$ \\
Actors in the context & $4(9.1 \%)$ \\
Timeline & $4(9.1 \%)$ \\
Indicators & $3(6.8 \%)$ \\
Sphere of influence &
\end{tabular}

described slightly differently for each context. Similarly, Chandani et al. developed a cross-country ToC of community health worker supplied medication in Ethiopia, Malawi and Rwanda. They compared whether each of the preconditions and the outcome was achieved in each setting [40]. These differences were then explained based on the contextual factors in each setting such as types of medication provided by the health workers, standard operating procedures and data availability and means of transport and travel times. Secker et al. [72] explored the influence of socioeconomic and demographic characteristics as well as infrastructure and organisational processes and systems between eight pilot sites in the evaluation of a preretirement health initiative.

\section{Using $\mathrm{ToC}$ to provide causal explanations}

Few papers reported on the identification of breakdowns and side effects, effectiveness or efficacy and causal explanation as described by Coryn et al. [4]. Only four (6.5\%) identified breakdowns of programme theory, three $(4.8 \%)$ identified unexpected consequences of the intervention, ten $(16.1 \%)$ made cause-and-effect associations between theoretical constructs explicit, two (3.2 \%) described differences in direction and/or strength of relationship between programme and outcomes and two (3.2\%) described the extent to which one construct accounted for/mediated the relationship between other constructs.

\section{Discussion}

In this systematic review, we provide an overview of how ToCs have been developed and used to develop and evaluate public health interventions. As expected, there is variation in how ToCs are developed and used in evaluation although the papers report very little detail about the ToC process.

We have shown that the ToC approach has been in use since at least 1999 with 62 papers found in peerreviewed journals and grey literature. This was significantly more than expected, given that Coryn et al. [4] found only three papers describing theory-driven evaluation of health interventions using ToC. However, Coryn et al. only included papers that reported the use of $\mathrm{ToC}$ for evaluation (rather than also describing the development of $\mathrm{ToC}$ or the use in the design of an intervention) and excluded those that did not provide enough detail [4].

In this review, many papers provided little detail in relation to the process of $\mathrm{ToC}$ development and how the ToC was used to design the intervention or conduct the evaluation. For example, Bonner [36] describes the ToC approach in detail but provides only a short example of the Health Action Zones experience of using $\mathrm{ToC}$ to evaluate an intervention to reduce drug taking. Brown et al. [37] reports using a ToC approach to evaluate a health promotion intervention for adolescents. The only description of $\mathrm{ToC}$ was found in the abstract and then mentioned briefly in the discussion. There was no clarity on how the $\mathrm{ToC}$ was developed or any explicit mention of how it was used to inform the analysis.

In contrast, other papers provided extensive detail on the ToC development process. For example, Hernandez and Hodges [12] describe the 12 step process used to develop a $\mathrm{ToC}$ for interagency delivery of mental health services for children with serious emotional disturbances and their families. They describe each step in detail including the purpose of the stage of the process, the types of stakeholders participating in the step, the substance of the discussions and the decisions reached. The ToC was then displayed as a logic model for readers to gain a better understanding of the output of the process. Similarly, Mookherji and LaFond [64] described in detail their approach to developing their initial $\mathrm{ToC}$ and how the $\mathrm{ToC}$ was used to determine case selection for a comparative case study. They then described how they used the results of the comparative case study and the $\mathrm{ToC}$ workshops to refine their ToC.

A range of methods were used to develop ToCs. The methods ranged from participatory methods which encourage stakeholder participation and ownership of the ToC such as workshops and working groups, to more evaluator focused approaches such as programme observation and review of programme documentation. Although the reason for the choice of methods was rarely made explicit by the authors, these methods were presumably chosen based on the purpose, depth and level of stakeholder buy-in the ToC required. For example, the examples of the development of systems of care for 
children and adolescents with mental and behavioural disorders viewed stakeholder participation as very important and therefore held a series of workshops with multiple stakeholders from different government departments, service providers, families and service users [12, 50, 61]. In some cases, although stakeholders were interviewed or participated in surveys, they did not contribute explicitly to the development of the ToC [16, 57]. Sullivan and Stewart [10] argue that although participation of all stakeholders in the development of $\mathrm{ToC}$ is the ideal presented by Weiss and colleagues [7], this is not always practical or feasible. They argue that different types of ToC development and resulting ownership may have advantages and therefore it is important to be explicit about the development process.

The lack of detail in most of the examples in this review makes it difficult to assess the thoroughness of ToC development. In many cases, the $\mathrm{ToC}$ seems to have been developed superficially and then used in a cursory way during evaluation. Similarly, where diagrams or narrative summaries of ToCs are presented in the papers, very little detail is included. Most authors present the long-term outcomes, sequence of change, beneficiaries and context. However, very few make their assumptions explicit although Vogel identifies these as a core part of ToC [8]. Where ToC was used to develop the interventions, it was often not clear how this was done apart from providing an overarching framework or strategic plan for the intervention.

A surprising finding of the review was the paucity of papers that describe the use of $\mathrm{ToC}$ for use during the implementation of the intervention $(n=2)$. Given the popularity of $\mathrm{ToC}$ as a monitoring and evaluation tool by international development agencies such as the Department for International Development, UK, [8], we had expected that more papers would use ToC during the implementation phase to assess progress towards the outcomes as well as modify implementation where necessary.

ToC theorists such as Connell and Kubisch [15] emphasise that the ToC approach to evaluation is method neutral and, as such, does not prescribe a specific type of study design or evaluation method. This was reflected in the papers included in this review which used a variety of qualitative and quantitative data collection and analysis methods. This flexibility in methods can be an advantage if researchers can design evaluations which seek to understand and evaluate both the outcomes and causal mechanisms which are made explicit in the ToC. However, flexibility in methods may also result in evaluations being poorly formulated in terms of the appropriateness of the methods, the rigor of data analysis or the results not interpreted in light of the ToC. In this review, evaluations were often described in detail but it was not clear how they linked to the $\mathrm{ToC}$ or how the $\mathrm{ToC}$ was used to interpret the results. However, some authors clearly develop or refine their ToCs as the results of the evaluation emerge. For example, Carroll et al. [39] sought to describe a theory of change for health promotion activities for hard to reach groups which was developed through the evaluation.

Most papers failed to explicitly discuss the results of the $\mathrm{ToC}$ in relation to unexpected outcomes, direction of causation and mediation of effects. This is similar to the conclusions drawn by Coryn et al. who report that programme theory was not used in any meaningful way to develop evaluation questions or plan and conduct and interpret the analysis [4].

It is interesting to note that no studies used ToC alongside RCTs as a method to unpack the programme theory underpinning the intervention. As we have noted previously, ToC holds much potential for this as RCTs alone are no longer considered adequate for the evaluation of complex health interventions [3].

Detailed reporting of the $\mathrm{ToC}$ process is particularly important as definitions of ToC differ considerably [8]. Many papers did not define ToC. However, there were clear overlaps with other theory-driven evaluation approaches, in particular, realist approaches [32, 36, 38, 56] and logic models $[12,26,31,52,54,61,65,66,68,69$, $76,82]$. Realist approaches have a different theoretical basis to ToC and differ in several ways including how they articulate and generate theory, the degree to which stakeholders are involved and the types of knowledge they seek to generate [20]. Marchal et al. [18], in a systematic review on realist evaluation in health systems research, also noted that $\mathrm{ToC}$ and realist evaluation were often used together or interchangeably. Logic models are conceptually similar to ToC but are usually presented in a linear form with boxes for inputs, activities, outputs and outcomes with little explanation of the causal pathways linking them [3]. Reducing a $\mathrm{ToC}$ to a logic model may conceal some of the explanatory power of the causal pathways.

Two limitations to this review are the lack of double data extraction and the inability to effectively measure the quality of the included papers. We did extract data on a checklist of ToC components proposed by Vogel [8] and principles of theory-driven evaluation by Coryn et al. [4], but it was difficult to make an assessment of quality. This is primarily because there is no agreed upon quality criteria for ToC. This is compounded by the flexibility of the ToC approach, both in the development of ToCs and how they can be used for evaluation. Because 
Table 5 Checklist for reporting ToC in Public Health Interventions

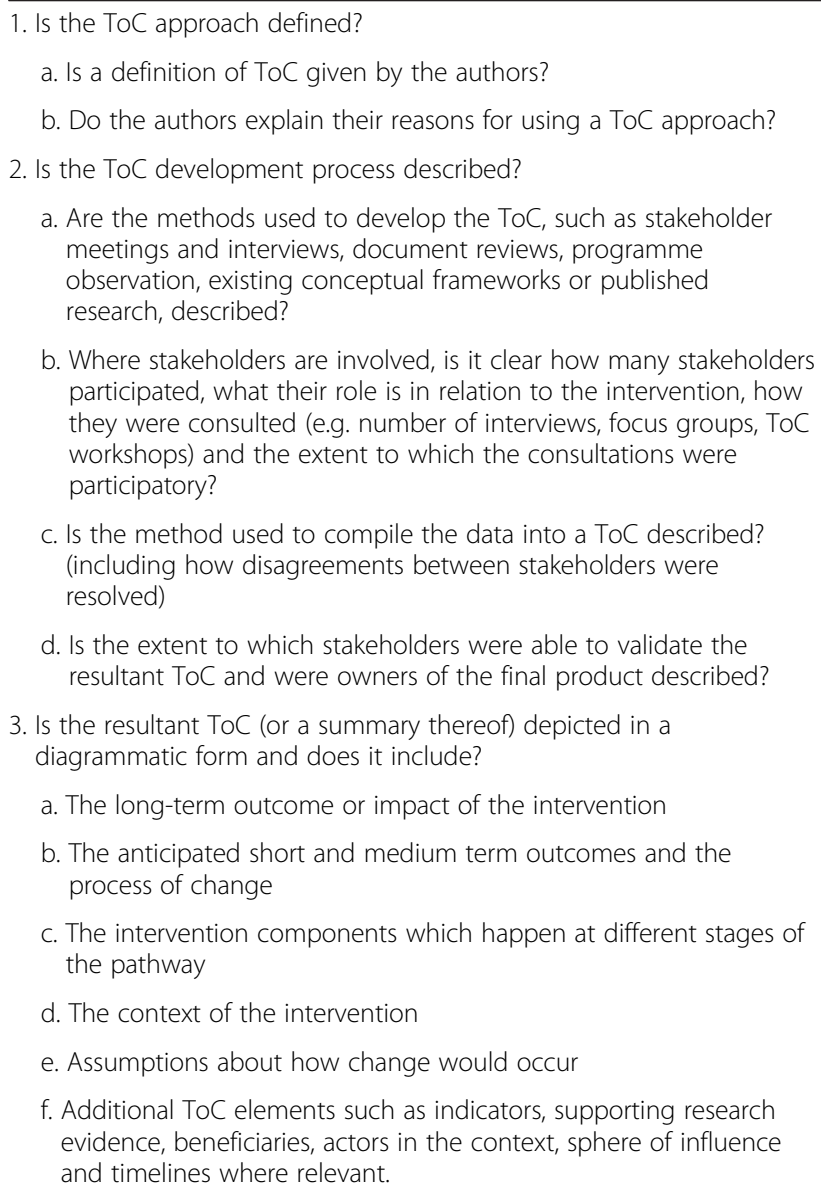

b. Where stakeholders are involved, is it clear how many stakeholders participated, what their role is in relation to the intervention, how they were consulted (e.g. number of interviews, focus groups, ToC workshops) and the extent to which the consultations were participatory?

c. Is the method used to compile the data into a ToC described? (including how disagreements between stakeholders were resolved)

d. Is the extent to which stakeholders were able to validate the resultant $\mathrm{ToC}$ and were owners of the final product described?

3. Is the resultant ToC (or a summary thereof) depicted in a diagrammatic form and does it include?

a. The long-term outcome or impact of the intervention

b. The anticipated short and medium term outcomes and the process of change

c. The intervention components which happen at different stages of the pathway

d. The context of the intervention

e. Assumptions about how change would occur

f. Additional ToC elements such as indicators, supporting research evidence, beneficiaries, actors in the context, sphere of influence and timelines where relevant.

4. Is the process of intervention development from the ToC described?

a. Are the methods of how interventions were refined from the ToC to something which can be implemented described? (For example, further stakeholder workshops, interviews, systematic literature reviews)

5. Is the way in which the ToC was used to develop and implement the evaluation described?

a. Are evaluation research questions generated from the ToC?

b. Is the role of ToC in the design, plan or conduct of the evaluation clear?

c. Does the paper describe the extent to which the key elements described in the $\mathrm{ToC}$ were measured in the evaluation (i.e. impact, short and medium term outcomes and the process of change, context, assumptions and the intervention)?

d. Does the paper describe whether and how process indicators were used to improve the quality of the intervention?

e. Is the role of the ToC in the analysis of the results of the evaluation clear?

$\mathrm{f}$. Is the role of ToC in the interpretation of the results of the evaluation described? (including the breakdown of programme theory, unanticipated outcomes and causation including the strength and direction of causal relationships) evaluations using ToC vary in study design and method, existing methodological checklists are of little use for comparative purposes.

We suggest that authors planning to report on $\mathrm{ToC}$ to guide the development or evaluation of public health interventions provide more detail on the ToC process to readers. In particular, it is important to make the $\mathrm{ToC}$ used explicit and this is usually easier in diagrammatic form. Complex ToCs can be simplified in a summary diagram with detailed ToCs provided as web appendices. This will help the reader to understand the authors' expected pathways of change and judge their validity. In addition, it is imperative that authors describe in detail how the ToC was developed and used. This is particularly important as there is no single way to develop or use a ToC. Making the process explicit helps readers judge the credibility of the $\mathrm{ToC}$ and strengthen the literature in this field.

We have therefore developed a checklist based on this review and the work of Coryn et al. [4] and Vogel [8] which can assist with the clearer reporting of the $\mathrm{ToC}$ approach. The checklist gives guidance as to which aspects of the ToC should be made explicit (Table 5). It covers five domains, namely the (1) definition of $\mathrm{ToC}$; (2) description of the ToC development process; (3) ToC diagram; (4) process of intervention development and (5) use of $\mathrm{ToC}$ in evaluation. The checklist would benefit from expert review and piloting in the real world. However, it provides a starting point for authors reporting a $\mathrm{ToC}$ approach. As ToC is method neutral, this checklist could also be used together with other existing checklists such as the CONSORT statement for RCTs [85], the STROBE guidelines for observational research [86] or CReDECI2 for complex intervention development and evaluation [87].

\section{Conclusion}

The $\mathrm{ToC}$ approach is widespread in the public health literature. Clear reporting of the $\mathrm{ToC}$ process and outputs is important to improve to allow the readers a thorough understanding of the work and allows them to judge the validity of the approach. We recommend that our proposed checklist is used and refined by authors reporting the $\mathrm{ToC}$ approach.

\section{Additional file}

Additional file 1: The use of Theory of Change to design, implement and evaluate Public Health Interventions: a systematic review protocol. (DOCX 202 kb) 


\section{Competing interests}

The authors declare that they have no competing interests.

\section{Authors' contributions}

EB designed the study under the guidance of MDS and CL. The protocol for the review was developed by $E B$ with input from $L L, M D S$ and $C L$. EB and $L L$ double screened all abstracts and full text papers. EB conducted the data extraction and drafted the manuscript. All authors gave feedback on the draft manuscript and read and approved the final manuscript

\section{Acknowledgements}

Our sincere thanks to Solange Durao, Nicola Foster and Florian Breuer for providing comments on an earlier draft of this paper.

\section{Funding}

$E B, C L$ and MDS are funded by UK aid from the UK Government, as part of the PRogramme for Improving Mental health carE (PRIME). However, the views expressed do not necessarily reflect the UK Government's official policies. MDS is also funded by an LSHTM Career Fellowship along with LL by Grand Challenges Canada as part of the Mental Health Innovation Network. The funders had no role in the design, data collection, analysis or writing of this report.

\section{Author details}

${ }^{1}$ Alan J. Flisher Centre for Public Mental Health, Department of Psychiatry and Mental Health, University of Cape Town, 46 Sawkins Road, Rondebosch 7700 Cape Town, South Africa. ${ }^{2}$ Centre for Global Mental Health, London School of Hygiene and Tropical Medicine, Keppel Street, London WC1E 7HT, UK.

Received: 9 October 2015 Accepted: 20 April 2016 Published online: 06 May 2016

\section{References}

1. Mackenzie M, O'Donnell C, Halliday E, Sridharan S, Platt S. Do health improvement programmes fit with MRC guidance on evaluating complex interventions? BMJ. 2010;340:c185. doi:10.1136/bmj.c185.

2. Ling T. Evaluating complex and unfolding interventions in real time. Evaluation. 2012;18:79-91. doi:10.1177/1356389011429629.

3. De Silva MJ, Breuer E, Lee L, Asher L, Chowdhary N, Lund C, et al. Theory of Change: a theory-driven approach to enhance the Medical Research Council's framework for complex interventions. Trials. 2014;15:267. doi:10.1186/1745-6215-15-267.

4. Coryn CLS, Noakes LA, Westine CD, Schroter DC. A systematic review of theory-driven evaluation practice from 1990 to 2009. Am J Eval. 2011;32:199-226. doi:10.1177/1098214010389321.

5. Funnell SC, Rogers PJ. Purposeful program theory: effective use of theories of change and logic models. 1st ed. San Francisco, CA: Jossey-Bass; 2011.

6. US Department of Health and Human Services, Centres for Disease Conro and Prevention, Office of the Director, Office of Strategy and Innovation. Introduction to program evaluation for public health programs: a self study guide. Atlanta, GA: Centres for Disease Control and Prevention; 2011.

7. Weiss C. Nothing as practical as good theory: exploring theory-based evaluation for comprehensive community initiatives for children and families. In: Connell JP, editor. New approaches to evaluating community initiatives: concepts, methods, and contexts. Washington, DC: Aspen Institute; 1995. p. 65-92.

8. Vogel I. Review of the use of 'Theory of Change' in international development. UK: Department for International Development (DFID); 2012.

9. Andersen A. A community builder's approach to theory of change: a practical guide to theory development. New York: The Aspen Insitute; 2004.

10. Sullivan H, Stewart M. Who owns the theory of change? Evaluation. 2006:12(2):179-99. doi:10.1177/1356389006066971.

11. Breuer E, De Silva M, Fekadu A, Luitel N, Murhar V, Nakku J, et al. Using workshops to develop theories of change in five low and middle income countries: lessons from the programme for improving mental health care (PRIME). Int J Ment Health Syst. 2014:8(1):15.

12. Hernandez M, Hodges S. Applying a theory of change approach to interagency planning in child mental health. Am J Community Psychol. 2006;38(3-4):165-73. doi:10.1007/s10464-006-9079-7.
13. Weitzman $B C$, Silver D, Dillman KN. Integrating a comparison group design into a theory of change evaluation: the case of the urban health initiative. Am J Eval. 2002;23(4):371-85. doi:10.1177/109821400202300402.

14. Knowlton LW, Phillips C. Corporate giving gets smarter: ConAgra Foods Foundation fights childhood hunger. Found Rev. 2012;4:2. doi:10.4087/ FOUNDATIONREVIEW-D-11-00034.1.

15. Connell JP, Kubisch AC. Applying a theory of change approach to the evaluation of comprehensive community initiatives: progress, prospects, and problems. In: Fulbright-Andersen K, Kubisch A, Connell JP, editors. New Approaches to Evaluating Community Initiatives, Vol. 2: Theory, Measurement, and Analysis United States of America: The Aspen Institute; 1998. p. 15-44

16. Bauer GF. Developing community health indicators to support comprehensive community building initiatives: a case study of a participatory action research project. University of California, Berkely, US: ProQuest Information \& Learning; 1999

17. Prinsen $\mathrm{G}$, Nijhof S. Between logframes and theory of change: reviewing debates and a practical experience. Dev Pract. 2015;25(2):234-46. doi:10. 1080/09614524.2015.1003532.

18. Marchal B, van Belle S, van Olmen J, Hoeree T, Kegels G. Is realist evaluation keeping its promise? A review of published empirical studies in the field of health systems research. Evaluation. 2012;18:192-212. doi:10.1177/ 1356389012442444

19. James $C$. Theory of change review: a report comissioned by Comic Relief; 2011. http://mande.co.uk/2012/uncategorized/comic-relief-theory-ofchange-review/.

20. Blamey A, Mackenzie M. Theories of change and realistic evaluation. Evaluation. 2007:13(4):439-55. doi:10.1177/1356389007082129.

21. Rychetnik L, Frommer M, Hawe $P$, Shiell A. Criteria for evaluating evidence on public health interventions. J Epidemiol Community Health. 2002:56:119-27.

22. Yin RK. Case study research: design and methods. Fourth ed. Applied Social Research Methods Series. Sage Publications; 2009

23. Endnote. Endnote. X7 ed. San Fransisco: Thomson Reuters; 2015.

24. Evernote Cooperation. California: Evernote Corporation; 2015.

25. Statcorp. STATA. 13th ed. College Station: Statcorp; 2013.

26. Andersen R, Nesman T, Hodges S. Expressing your ideas: using a logic model to create system change USF logic model team, Tampa, Florida. University of South Florida: Tools for Creating and Sustaining Human Services: Theory of Change Logic Models; 2012.

27. Andreas D, Ja DY, Wilson S. Peers reach out supporting peers to embrace recovery (PROSPER): a center for substance abuse treatment recovery community services program. Alcohol Treat Q. 2010;28(3):326-38. doi:10. 1080/07347324.2010.488538

28. AusAID. AUusAID's mulitsectoral contribution to the national response in Papua New Guinea. Annex 10 Theory of Change 2010. http://www.ode. ausaid.gov.au/publications/documents/pnghiv/annex10-theoryofchange.pdf. Accessed date 16 Jan 2014.

29. Bacchus LJ, Bewley S, Vitolas CT, Aston G, Jordan P, Murray SF. Evaluation of a domestic violence intervention in the maternity and sexual health services of a UK hospital. Reprod Health Matters. 2010;18(36):147-57. doi:10.1016/ s0968-8080(10)36526-810.1136/.

30. Barton WH, Powers GT, Morris ES, Harrison A. Evaluating a comprehensive community initiative for children, youth, and families. Adolesc Family Health. 2001;2(1):27-36.

31. Basson HA, Roets L. Workplace wellness for HIV/AIDS affected nurses in South Africa. Br J Nurs. 2013;22(1):38-44.

32. Bauld $L$, Judge $K$, Barnes M, Benzeval M, MacKenzie M, Sullivan $H$. Promoting social change: the experience of health action zones in England. J Soc Policy. 2005;34(3):427-45. doi:10.1017/S0047279405008858.

33. Beeston C, Robinson M, Craig N. Monitoring and evaluating Scotland's alcohol strategy. Setting the scene: theory of change and baseline picture. Edinburgh: NHS Health Scotland; 2011.

34. Bhattacharjee P. Use of theory of change to guide the design and monitoring of an intervention intended to reduce partner violence and increase protected sex among sex workers. STRIVE Ann Meet. 2013.

35. Birkby BW. The design and implementation of an evaluation for a comprehensive community-wide initiative on child maltreatment (Kentucky). Kentucky University, US: ProQuest Information \& Learning; 2001.

36. Bonner L. Using theory-based evaluation to build evidence-based health and social care policy and practice. Crit Public Health. 2003;13(1):77-92. doi:10.1080/0958159031000100224 
37. Brown EC, Hawkins JD, Rhew IC, Shapiro VB, Abbott RD, Oesterle S et al. Prevention system mediation of communities that care effects on youth outcomes. Prev Sci. 2013:1-10. doi:10.1007/s11121-013-0413-7

38. Carr SM, Lhussier M, Wilkinson J, Gleadhill S. Empowerment evaluation applied to public health practice. Crit Public Health. 2008;18(2):161-74. doi:10.1080/09581590701499327.

39. Carroll M, David M, Jacobs B, Judge K, Wilkes B. A realistic/theory of change approach to the evaluation of health promotion in small- and medium-sized enterprises in Sandwell. Soc Policy Soc. 2005;4(4):393.

40. Chandani Y, Noel M, Pomeroy A, Andersson S, Pahl MK, Williams T. Factors affecting availability of essential medicines among community health workers in Ethiopia, Malawi, and Rwanda: solving the last mile puzzle. Am J Trop Med Hyg. 2012;87(5):120-6. doi:10.4269/ajtmh.2012. 11-0781.

41. Cole DC, Hogg-Johnson S, Manno M, Ibrahim S, Wells RP, Ferrier SE, et al. Reducing musculoskeletal burden through ergonomic program implementation in a large newspaper. Int Arch Occup Environ Health. 2006;80(2):98-108. doi:10.1007/s00420-006-0107-6.

42. De La Rosa IA, Perry J, Dalton LE, Johnson V. Strengthening families with first-born children: exploratory story of the outcomes of a home visiting intervention. Res Soc Work Pract. 2005;15(5):323-38. doi:10.1177/ 1049731505277004

43. De La Rosa IA, Perry J, Johnson V. Benefits of increased home-visitation services: exploring a case management model. Family Community Health. 2009;32(1):58-75.

44. Dixon-Woods M, Bosk CL, Aveling EL, Goeschel CA, Pronovost PJ. Explaining Michigan: developing an ex post theory of a quality improvement program. Milbank Q. 2011;89(2):167-205. doi:10.1111/j.1468-0009.2011.00625.x.

45. Dixon-Woods M, Tarrant C, Willars J, Suokas A. How will it work? A qualitative study of strategic stakeholders' accounts of a patient safety initiative. Qual Saf Health Care. 2010;19(1):74-8. doi:10.1136/qshc.2008. 029504

46. Goss-Power PJ. Evaluation of a school-based program for youth with emotional and behavioral disabilities. New England Graduate School, US: ProQuest Information \& Learning; 2005.

47. Gray P, Seddon T. Prevention work with children disaffected from school: findings from the evaluation of two innovative community-based projects. Health Educ. 2005;105(1):62-72. doi:10.1108/09654280510572312.

48. Gregor M. TB alert change story map: charities evaluation services: National Performance Programme. London: Charities Evaluation Services; 2009. http://www.ces-vol.org.uk/Resources/CharitiesEvaluationServices/ Documents/tbalertchangestorymaptoc-802-810.pdf. Accessed date 16 Jan 2014.

49. Henderson PM. Program evaluation of a long-term substance abuse treatment program for homeless men. US: ProQuest Information \& Learning; 2004.

50. Illinois Caucus for Adolescent Health. Strategic Plan. 2013. http://icah.org/ about/\#strategic-plan. Accessed 16th January 2014

51. Kemp L, Harris E, McMahon C, Matthey S, Vimpani G, Anderson T, et al. Benefits of psychosocial intervention and continuity of care by child and family health nurses in the pre- and postnatal period: process evaluation. J Adv Nurs. 2013;69(8):1850-61. doi:10.1111/jan.12052.

52. Kreger M, Sargent K, Arons A, Standish M, Brindis CD. Creating an environmental justice framework for policy change in childhood asthma: a grassroots to treetops approach. Am J Public Health. 2011;101 Suppl 1:S208-16. doi:10.2105/ajph.2011.300188.

53. Levinson-Johnson J. Monroe Country ACCESS Logic Model. Tools for creating and sustaining human services: theory of change logic models: University of South Florida 2012

54. Levison-Johnson J, Wenz-Gross M. From complexity to reality: providing useful frameworks for defining systems of care. Eval Program Plann. 2010; 33(1):56-8. doi:10.1016/j.evalprogplan.2009.05.005.

55. Lund C, Tomlinson M, de Silva M, Fekadu A, Shidhaye R, Jordans M, et al. PRIME: a programme to reduce the treatment gap for mental disorders in five low- and middle-income countries. PLoS Med. 2012;9(12):e1001359. doi:10.1371/journal.pmed.1001359.

56. Macfarlane F, Greenhalgh T, Humphrey C, Hughes J, Butler C, Pawson R. A new workforce in the making?: a case study of strategic human resource management in a whole-system change effort in healthcare. J Health, Organ Manag. 2011;25(1):55-72. doi:10.1108/ 14777261111116824
57. Mackenzie M. Benefit or burden: introducing paraprofessional support staff to health visiting teams: the case of Starting Well. Health Soc Care Community. 2006;14(6):523-31. doi:10.1111/j.1365-2524.2006.00640.x.

58. Mackenzie M, Blamey A. The practice and the theory: lessons from the application of a theories of change approach. Evaluation. 2005;11(2):151-68. doi:10.1177/1356389005055538.

59. Mackenzie M, Blamey A, Halliday E, Maxwell M, McCollam A, McDaid D, et al. Measuring the tail of the dog that doesn't bark in the night: the case of the national evaluation of Choose Life (the national strategy and action plan to prevent suicide in Scotland). BMC Public Health. 2007;7:146. doi:10.1186/1471-2458-7-146.

60. Mackenzie M, Reid M, Turner F, Wang YY, Clarke J, Sridharan S, et al. Reaching the hard-to-reach: conceptual puzzles and challenges for policy and practice. J Soc Policy. 2012;41(03):511-32. doi:10.1017/ S0047279412000074.

61. Maselli B. Thrive community youth logic model: working together for a brighter tomorrow Lewiston, Maine. Tools for Creating and Sustaining Human Services: Theory of Change Logic Models: University of South Florida 2012

62. Mason P. Visual data in applied qualitative research: lessons from experience. Qual Res. 2005;5(3):325-46. doi:10.1177/1468794105054458.

63. McQuiston C, Choi-Hevel S, Clawson M. Protegiendo nuestra comunidad: empowerment participatory education for HIV prevention. J Transcult Nurs. 2001;12(4):275-83.

64. Mookherji S, LaFond A. Strategies to maximize generalization from multiple case studies: lessons from the Africa Routine Immunization System Essentials (ARISE) project. Evaluation. 2013;19(3):284-303. doi:10.1177/ 1356389013495212

65. Morilus-Black M, McCarthy V, Kernan JB. Using a logic model as a tool to apply a theory of change approach to support implementation, evaluation and strategic planning. Tools for creating and sustaining human services: theory of change logic models: University of South Florida 2012

66. Reid M, Botma Y. A framework to expand public services to children with biomedical healthcare needs related to HIV in the Free State, South Africa. Afr J Aids Res. 2012;11(2):91-8. doi:10.2989/16085906.2012.698054.

67. Riley AJ, Byng R, White C, Smith S. Utilising theories of change to understand the engagement of general practitioners in service improvement: a formative evaluation of the Lewisham Depression Programme. Qual Prim Care. 2008;16(1):17-26.

68. Rivera JA, Martorell R, Gonzalez W, Lutter C, Cossio TG, Flores-Ayala R, et al. Prevención de la desnutrición de la madre y el niño: el componente de nutrición de la Iniciativa Salud Mesoamérica 2015. Salud Publica Mex. 2011; 53 Suppl 3:S303-11.

69. Rodriguez MH, Betanzos-Reyes AF. Grupo de Trabajo de Malaria del Sistema Mesoamericano de Salud P. Plan de mejoramiento del control de la malaria hacia su eliminación en Mesoamérica. Salud Publica Mex. 2011;53 Suppl 3:S333-48.

70. Scanlon DP, Beich J, Alexander JA, Christianson JB, Hasnain-Wynia R, McHugh MC, et al. The aligning forces for quality initiative: background and evolution from 2005 to 2012. Am J Manag Care. 2012;18:S115-25.

71. Schierhout G, Hains J, Si D, Kennedy C, Cox R, Kwedza R, et al. Evaluating the effectiveness of a multifaceted, multilevel continuous quality improvement program in primary health care: developing a realist theory of change. Implementation Sci. 2013;8(1):119. doi:10.1186/1748-5908-8-119.

72. Secker J, Bowers H, Webb D, Llanes M. Theories of change: what works in improving health in mid-life? Health Educ Res. 2005;20(4):392-401. doi:10.1093/her/cyg133.

73. Smith N, Barnes M. New jobs old roles—working for prevention in a wholesystem model of health and social care for older people. Health Soc Care Community. 2013;21(1):79-87. doi:10.1111/j.1365-2524.2012.01089.x.

74. Suarez-Balcazar Y. Empowerment and participatory evaluation of a community health intervention: Implications for occupational therapy. OTJR Occup Participation Health. 2005;25(4):133-42

75. Tran L. A theory of change for mental health advocacy: a case study Charities evaluation services; 2009. http://www.cesvol.org.uk/Resources/ CharitiesEvaluationServices/Documents/kingsfundtoccasestudy-801-809.pdf. Accessed date 16 Jan 2014

76. Tucker $P$, Liao Y, Giles WH, Liburd L. The REACH 2010 logic model: an illustration of expected performance. Prev Chronic Dis. 2006;3(1):A21.

77. Vander Stoep A, Williams M, Jones R, Green L, Trupin E. Families as full research partners: what's in it for us? J Behav Health Serv Res. 1999;26(3):329-44. 
78. Veerman JW, De Kemp RAT, Ten Brink LT, Slot NW, Scholte EM. The implementation of families first in the Netherlands: a one year follow-up. Child Psychiatry Hum Dev. 2003;33(3):227-44. doi:10.1023/a:1021456630670.

79. von dem Knesebeck O, Joksimovic L, Badura B, Siegrist J. Evaluation of a community-level health policy intervention. Health Policy. 2002;61 (1):111-22.

80. Walker JS, Matarese M. Using a theory of change to drive human resource development for wraparound. J Child Family Studies. 2011;20(6):791-803. doi:10.1007/s10826-011-9532-6.

81. Weitzman BC, Mijanovich T, Silver D, Brecher C. Finding the impact in a messy intervention: using an integrated design to evaluate a comprehensive citywide health initiative. Am J Eval. 2009;30(4):495-514. doi:10.1177/ 1098214009347555.

82. Wenz-Gross W, DuBrino T. Central Massachusetts Communities of Care: applying a theory of change approach to support implementation, evaluation, and strategic planning. Tools for Creating and Sustaining Human Services: Theory of Change Logic Models: University of South Florida 2012.

83. Moher D, Liberati A, Tetzlaff J, Altman DG. Preferred reporting items for systematic reviews and meta-analyses: the PRISMA statement. PLoS Med. 2009;6, e1000097. doi:10.1371/journal.pmed.1000097.

84. Clarke DJ, Godfrey M, Hawkins R, Sadler E, Harding G, Forster A, et al. Implementing a training intervention to support caregivers after stroke: a process evaluation examining the initiation and embedding of programme change. Implementation Sci. 2013;8(1):96. doi:10.1186/1748-5908-8-96.

85. Schulz KF, Altman DG, Moher D. CONSORT 2010 statement: updated guidelines for reporting parallel group randomised trials. BMC Med. 2010;8(1):18.

86. Vandenbroucke JP, Von Elm E, Altman DG, Gøtzsche PC, Mulrow CD, Pocock $\mathrm{SJ}$, et al. Strengthening the Reporting of Observational Studies in Epidemiology (STROBE): explanation and elaboration. Ann Intern Med. 2007;147(8):W-163-94.

87. Möhler R, Köpke S, Meyer G. Criteria for Reporting the Development and Evaluation of Complex Interventions in healthcare: revised guideline (CReDECI 2). Trials. 2015;16(1):204

\section{Submit your next manuscript to BioMed Central and we will help you at every step:}

- We accept pre-submission inquiries

- Our selector tool helps you to find the most relevant journal

- We provide round the clock customer support

- Convenient online submission

- Thorough peer review

- Inclusion in PubMed and all major indexing services

- Maximum visibility for your research

Submit your manuscript at www.biomedcentral.com/submit

C Biomed Central 